\title{
Effect of Coronary Bypass and Valve Structure on Outcome in Isolated Valve Replacement for Aortic Stenosis
}

\author{
William Clifford Roberts, MD ${ }^{\mathrm{a}, \mathrm{b}, \mathrm{d}, *}$, Carey Camille Roberts ${ }^{\mathrm{d}, \mathrm{g}}$, Travis James Vowels ${ }^{\mathrm{d}, \mathrm{h}}$, \\ Jong Mi Ko, BA ${ }^{\mathrm{d}}$, Giovanni Filardo, PhD, MPH ${ }^{\mathrm{e}, \mathrm{f}}$, Baron Lloyd Hamman, $\mathrm{MD}^{\mathrm{c}}$, \\ Gregory John Matter, $\mathrm{MD}^{\mathrm{c}}$, Albert Carl Henry III, MD ${ }^{\mathrm{c}}$, and Robert Frederick Hebeler, Jr., $\mathrm{MD}^{\mathrm{c}}$
}

\begin{abstract}
Reports differ regarding the effect of concomitant coronary artery bypass grafting (CABG) in patients who undergo aortic valve replacement (AVR) for aortic stenosis (AS), and no reports have described the effect of aortic valve structure in patients who undergo AVR for AS. A total of 871 patients aged 24 to 94 years (mean 70) whose AVR for AS was their first cardiac operation, with or without first concomitant CABG, were included. Patients who underwent mitral valve procedures were excluded. In comparison with the 443 patients (51\%) who did not undergo CABG, the 428 (49\%) who underwent concomitant CABG were significantly older, were more often male, had lower transvalvular peak systolic pressure gradients and larger valve areas, had lower frequencies of congenitally malformed aortic valves, had lighter valves by weight, had higher frequencies of systemic hypertension, and had longer stays in the hospital after AVR. Early and late (to 10 years) mortality were similar by propensity-adjusted analysis in patients who did and did not undergo concomitant CABG. Congenitally unicuspid or bicuspid valves occurred in approximately $90 \%$ of those aged 21 to 50 , in nearly $70 \%$ in those aged 51 to 70 years, and in just over $30 \%$ in those aged 71 to 95 years. Unadjusted and adjusted survival was significantly higher in patients with unicuspid or bicuspid valves compared to those with tricuspid valves. In conclusion, although concomitant CABG had no effect on the adjusted probability of survival, the type of aortic valve (unicuspid or bicuspid vs tricuspid) significantly affected the unadjusted and adjusted probability of survival. () 2012 Elsevier Inc. All rights reserved. (Am J Cardiol 2012;109:1334-1340)
\end{abstract}

Adults with isolated (no mitral valve disease) aortic stenosis (AS) (with or without aortic regurgitation) frequently have associated narrowing of $\geq 1$ major (right, left main, left anterior descending, or left circumflex) epicardial coronary arteries. In reported patients who undergo aortic valve replacement (AVR) for AS, the effect of concomitant coronary artery bypass grafting $(\mathrm{CABG})$ on early and late mortality has been variable. The aim of this study was to compare among patients with isolated AS the outcomes of AVR in patients with versus without CABG and also the effect of aortic valve structure (unicuspid or bicuspid vs tricuspid) on the probability of long-term survival after AVR for AS.

\section{Methods}

The surgical pathology files of the cardiovascular laboratory, a part of the pathology department at Baylor

Departments of anternal Medicine (Division of Cardiology), ${ }^{b}$ Pathology, and ${ }^{\mathrm{c} C a r d i o t h o r a c i c ~ S u r g e r y ~ a n d ~ t h e ~}{ }^{\mathrm{d} B a y l o r ~ H e a r t ~ a n d ~ V a s c u l a r ~}$ Institute, Baylor University Medical Center; ${ }^{\mathrm{e}}$ Institute for Health Care Research and Improvement, Baylor Health Care System; f Department of Statistical Science, Southern Methodist University, Dallas Texas; ${ }^{\mathrm{g}}$ University of Georgia, Athens, Georgia; and heniversity of Texas at Austin, Austin, Texas. Manuscript received December 5, 2011; revised manuscript received and accepted December 8, 2011.

*Corresponding author: Tel: 214-820-7911; fax: 214-820-7533.

E-mail address: wc.roberts@baylorhealth.edu (W.C. Roberts).
University Medical Center (BUMC) in Dallas, were searched for patients having operatively excised aortic valves without simultaneous replacement of the mitral valve or evidence of mitral stenosis. From January 2002 through June 2010 (102 months [8.5 years]), a total of 1,040 operatively excised stenotic aortic valves were submitted to the cardiovascular laboratory at BUMC. Each was described, and the surgical report was prepared by W.C.R. and photographed by J.M.K. The valve structure in each was determined by W.C.R from examination of the operatively excised aortic valve. This study was approved by the Institutional Review Board at BUMC on May 5, 2010, and the requirement for individual patient consent was waived.

Included in the present study were 871 adults whose AVR for AS was their first cardiac operation, with or without first simultaneous CABG. Patients who underwent isolated AVR for AS and later in a second operation underwent CABG or vice versa were excluded.

Clinical records, including admission note, discharge summary, echocardiographic and cardiac catheterization reports, and operative records, were sought from the patients' medical charts and/or BUMC Apollo cardiovascular database (Apollo Advance c/s version 4.2.13; LUMEDX Corporation, Oakland, California). (The Apollo system became operational at BUMC in January 2002.)

Echocardiographic and hemodynamic data were obtained from the cardiovascular computer database. Whether simultaneous CABG was performed at the time 
Table 1

Frequency of concomitant coronary artery bypass grafting in patients who underwent isolated aortic valve replacement for aortic stenosis $(\mathrm{n}=871)$

\begin{tabular}{|c|c|c|c|}
\hline \multirow[t]{2}{*}{ Variable } & \multicolumn{2}{|c|}{ Coronary Artery Bypass Grafting } & \multirow[b]{2}{*}{$\begin{array}{c}\mathrm{p} \\
\text { Value }\end{array}$} \\
\hline & $\begin{array}{c}\text { Yes } \\
(\mathrm{n}=428[49 \%])\end{array}$ & $\begin{array}{c}\text { No } \\
(\mathrm{n}=443[51 \%])\end{array}$ & \\
\hline Age group (years) & & & $<0.001$ \\
\hline $21-50$ & $12(3 \%)$ & $54(12 \%)$ & \\
\hline $51-70$ & $139(32 \%)$ & $201(45 \%)$ & \\
\hline $71-95$ & $277(65 \%)$ & $188(42 \%)$ & \\
\hline Gender & & & $<0.001$ \\
\hline Male & $289(68 \%)$ & $233(53 \%)$ & \\
\hline Female & $139(32 \%)$ & $210(47 \%)$ & \\
\hline Race & & & 0.953 \\
\hline White & $354(83 \%)$ & $367(83 \%)$ & \\
\hline Black & $24(6 \%)$ & $22(5 \%)$ & \\
\hline Hispanic & $16(4 \%)$ & $19(4 \%)$ & \\
\hline Other or unknown & $34(8 \%)$ & $35(8 \%)$ & \\
\hline Number of major coronary arteries narrowed $\geq 50 \%$ & $(\mathrm{n}=205)$ & $(\mathrm{n}=272)$ & $<0.001$ \\
\hline 0 & $32(16 \%)^{*}$ & $246(90 \%)$ & \\
\hline 1 & $60(29 \%)$ & $20(7 \%)$ & \\
\hline 2 & $68(33 \%)$ & $5(2 \%)$ & \\
\hline 3 & $34(17 \%)$ & $1(<1 \%)$ & \\
\hline 4 & $11(5 \%)$ & 0 & \\
\hline $\begin{array}{l}\mathrm{LV} \text {-aorta peak systolic gradient }(\mathrm{mm} \mathrm{Hg})(\mathrm{n}=475) \text {, } \\
\text { range (mean) [median] }\end{array}$ & $10-119(46)[41]$ & $11-154(54)[52]$ & $<0.001$ \\
\hline Aortic valve area $\left(\mathrm{cm}^{2}\right)(\mathrm{n}=474)$, mean $\pm S D$ & $0.85 \pm 0.31$ & $0.76 \pm 0.25$ & 0.008 \\
\hline Aortic valve structure & & & $<0.001$ \\
\hline Unicuspid & $11(3 \%)$ & $49(11 \%)$ & \\
\hline Bicuspid & $142(33 \%)$ & $243(55 \%)$ & \\
\hline Tricuspid & $275(64 \%)$ & $151(34 \%)$ & \\
\hline Aortic valve weight (g) & & & $<0.001$ \\
\hline Unicuspid, range (mean) [median] & $1.20-4.78(2.89)[2.71]$ & $1.19-7.15(3.47)[3.28]$ & \\
\hline Bicuspid, range (mean) [median] & $0.67-18.38(3.11)[2.62]$ & $0.81-9.68(3.11)[2.91]$ & \\
\hline Tricuspid, range (mean) [median] & $0.43-6.40(2.00)[1.84]$ & $0.55-5.63(2.11)[1.98]$ & \\
\hline Systemic hypertension by history & $324(76 \%)$ & $292(66 \%)$ & 0.015 \\
\hline Body mass index $\left(\mathrm{kg} / \mathrm{m}^{2}\right)$ & & & 0.872 \\
\hline$\leq 25$ & $148(35 \%)$ & $140(32 \%)$ & \\
\hline$>25-30$ & $156(37 \%)$ & $136(31 \%)$ & \\
\hline$>30-40$ & $104(24 \%)$ & $141(32 \%)$ & \\
\hline$>40$ & $18(4 \%)$ & $22(5 \%)$ & \\
\hline Range (mean $\pm \mathrm{SD})$ & $15-69(28 \pm 6)$ & $15-61(29 \pm 6)$ & \\
\hline $\begin{array}{l}\text { Days in hospital postoperatively in patients living }>30 \\
\text { days, range (mean) [median] }\end{array}$ & $3-53(10)[8]$ & $3-71(8)[6]$ & 0.001 \\
\hline Died $\leq 30$ days postoperatively & $29 / 427(7 \%)$ & $18 / 437(4 \%)$ & 0.179 \\
\hline Ascending aorta replaced & $11(3 \%)$ & $26(6 \%)$ & 0.159 \\
\hline Implanted valve type & & & $<0.001$ \\
\hline Mechanical & $64(16 \%)$ & $140(32 \%)$ & \\
\hline Bioprosthetic & $355(84 \%)$ & $289(67 \%)$ & \\
\hline Ross procedure & $1(<1 \%)$ & $6(1 \%)$ & \\
\hline
\end{tabular}

* These patients had significant narrowing of a branch of $\geq 1$ major coronary artery.

of AVR was also obtained from either the computer database or from the medical records. Information regarding the death of any patient was obtained from 3 sources: (1) the medical records in the deaths during the hospitalization at the time of AVR, (2) the Society of Thoracic Surgeons National Database, and (3) the Social Security Death Index for posthospitalization deaths. Echocardiographic data preoperatively were available for 426 patients (49\%). Cardiac catheterization data preoperatively were available for 561 patients $(64 \%)$.

Means, standard deviations, and percentages were calculated to describe the study cohort $(\mathrm{n}=871)$. Differ- ences in demographic, clinical, and morphologic details were tested using Wilcoxon's tests (for continuous variables) or chi-square tests (for categorical variables). Bonferroni's correction was used to account for multiplicity. Unadjusted $\mathrm{p}$ values, odds ratios, hazard ratios, 95\% confidence intervals (CIs), and log-rank statistics were estimated to describe 30-day and long-term mortality. Kaplan-Meier plots were used to describe unadjusted survival in patients who underwent concomitant CABG compared to those who did not and in patients with unicuspid or bicuspid valves compared to those with tricuspid valves. 

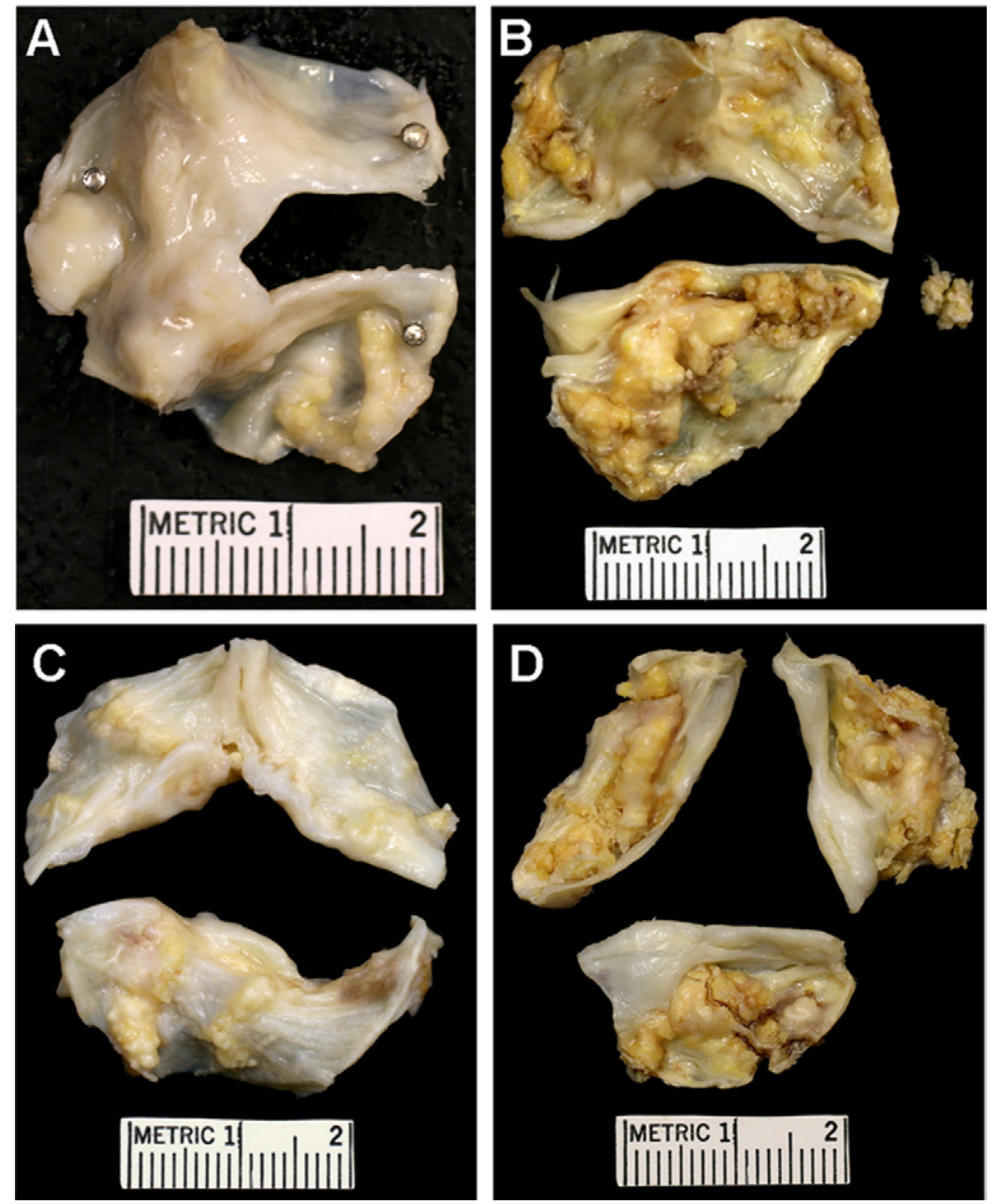

Figure 1. Photographs of operatively excised stenotic aortic valves in 4 patients. (A) Congenitally unicuspid unicommissural valve in a 66-year-old patient. (B) Congenitally bicuspid valve in an 81-year-old man. (C) Congenitally bicuspid valve in a 58-year-old man. $(D)$ Tricuspid aortic valve in a 79-year-old woman. CABG was performed also in patients whose valves are shown in $(B)$ and $(D)$. Valve weights were $2.48 \mathrm{~g}(A), 3.55 \mathrm{~g}(B), 3.19 \mathrm{~g}$ $(C)$, and $2.71 \mathrm{~g}(D)$.

A propensity score approach was used to assess the adjusted association between undergoing concomitant CABG (vs not) and 30-day and long-term mortality. ${ }^{1,2}$ To estimate the propensity score, we used a logistic regression model with receiving concomitant CABG (vs not) as the dependent variable and age, gender, race, body mass index, aortic valve structure, valve weight, systemic hypertension, ascending aorta replaced, and type of implanted valve as independent variables. Restricted cubic splines were used for all continuous variables. ${ }^{3,4}$ Multiple imputation via predictive mean matching was used to account for missing data regarding the independent variables in this model. ${ }^{1}$ Estimates from the aforementioned propensity model were then used to adjust the effect of concomitant CABG on 30-day mortality in a logistic regression model and on long-term mortality in a Cox proportional-hazards model. Possible effect modification by gender and age was investigated for the 2 models and ruled out. The Grambsch and Therneau test statistic was used to test for proportionality of hazards in the Cox model. $^{5}$

The same approach, controlling for the same con- founding factors except that valve structure was replaced by concomitant CABG, was used to assess the adjusted association between valve structure (unicuspid or bicuspid vs tricuspid valve structure) and 30-day and longterm mortality.

Statistical analyses were performed using SAS version 9.2 (SAS Institute Inc., Cary, North Carolina) and R software version 2.12.1 (R Project for Statistical Computing, Vienna, Austria).

\section{Results}

Demographic, clinical, and morphologic findings in the 871 patients included in the present study and their comparison between those with versus without concomitant CABG are listed in Table 1. Of the 871 patients, 428 (49\%) underwent concomitant CABG, and $443(51 \%)$ did not. In comparison to the group that did not undergo $\mathrm{CABG}$, those who underwent concomitant $\mathrm{CABG}$ were significantly older, were more often male, had lower transvalvular peak systolic pressure gradients and larger valve areas, had higher frequencies of tricuspid aortic 


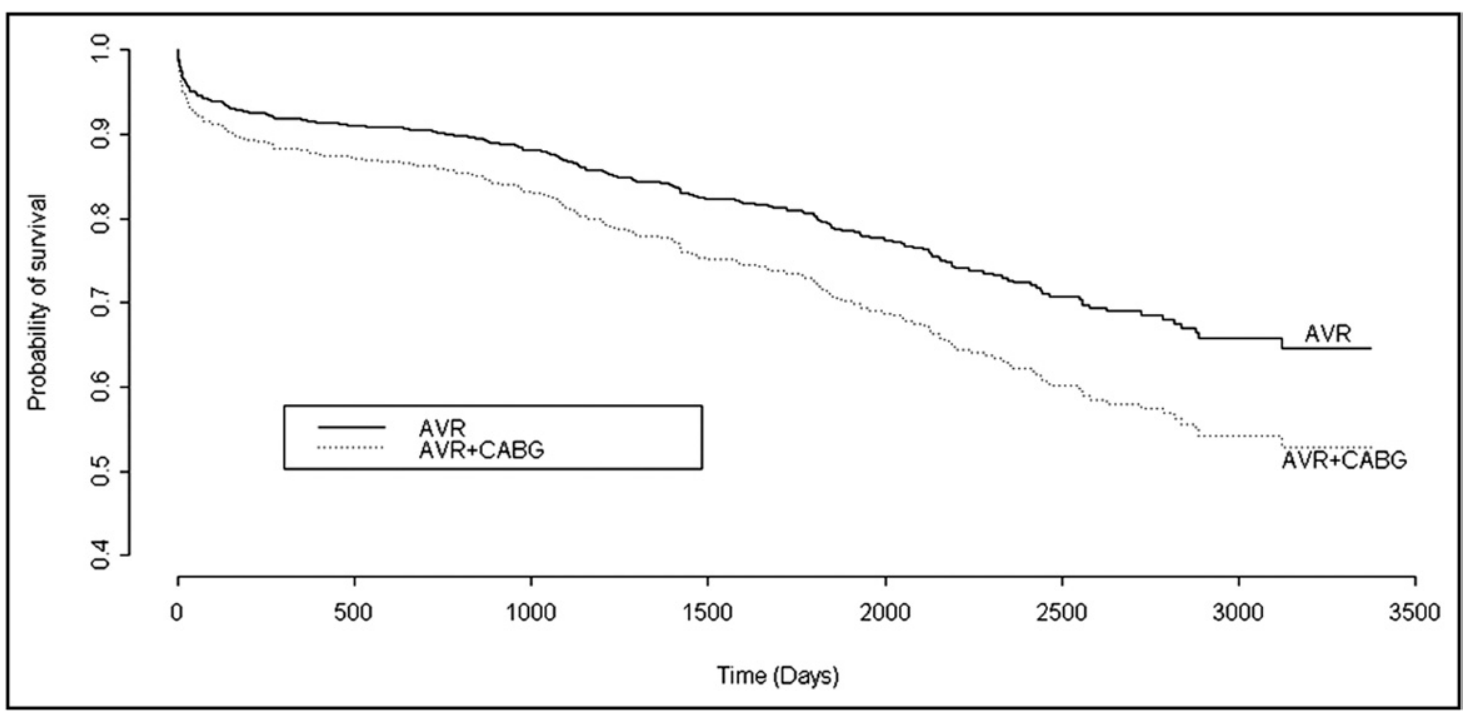

Figure 2. Unadjusted (Kaplan-Meier) curves depicting the probability of long-term survival in the patients who underwent compared to those who did not undergo concomitant coronary artery bypass grafting with the aortic valve replaced for stenosis (unadjusted hazard ratio $1.46,95 \%$ CI 1.12 to $1.91, \log$-rank $\mathrm{p}=0.005)$.

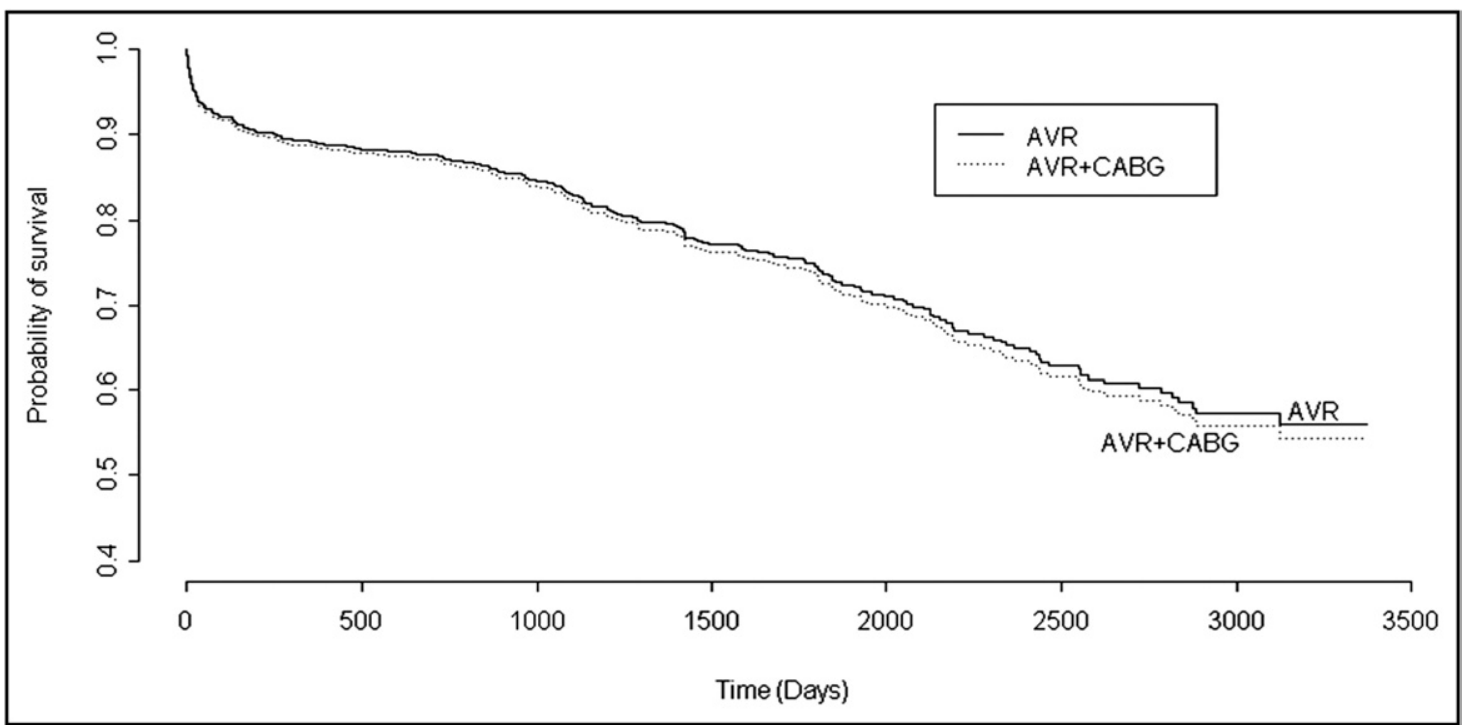

Figure 3. Adjusted (proportional-hazards model) curves depicting no significant difference in long-term survival in those who underwent compared to those who did not undergo concomitant coronary artery bypass grafting. The propensity-adjusted model included the following risk factors: age, gender, race, body mass index, aortic valve structure, valve weight, systemic hypertension, ascending aorta replaced, and type of implanted valve (adjusted hazard ratio 1.01, $95 \%$ CI 0.74 to 1.34 , adjusted $\mathrm{p}=0.976)$.

valves and lower frequencies of congenitally malformed aortic valves (Figure 1), had lighter aortic valves by weight, had higher frequencies of systemic hypertension, and had longer stays in the hospital after AVR (Table 1). Unadjusted early mortality (30 days) was not significantly (odds ratio $1.59,95 \%$ CI 0.89 to 2.85 ) different between those who underwent (29 deaths [7\%]) and those who did not undergo (18 deaths [4\%]) simultaneous CABG. The length of stay for patients surviving $>30$ days and long-term survival (up to 10-year follow-up) were significantly higher in those who underwent concomitant $\mathrm{CABG}$ (median length of stay 8 days vs 6 days for patients who did not undergo concomitant CABG, $p$
$=0.001$; unadjusted hazard ratio for survival $1.46,95 \%$ CI 1.12 to $1.91, \log$-rank $p=0.005)$. The unadjusted survival curves are depicted in Figure 2. However, after adjustment for possible confounders (age, gender, race, body mass index, aortic valve structure, valve weight, systemic hypertension, ascending aorta replaced, and type of implanted valve), neither early mortality (30 days; adjusted odds ratio $1.69,95 \%$ CI 0.87 to 3.29 ) nor long-term mortality (10-year follow-up; adjusted hazard ratio $1.01,95 \%$ CI 0.74 to 1.34 ) was different between those who did and did not undergo simultaneous CABG. The adjusted long-term survival curves are depicted in Figure 3. 
Table 2

Comparison of aortic valve structure in patients who underwent isolated aortic valve replacement for aortic stenosis with or without concomitant coronary artery bypass grafting $(n=871)$

\begin{tabular}{|c|c|c|c|c|}
\hline \multirow[t]{2}{*}{ Variable } & \multicolumn{3}{|c|}{ Aortic Valve Structure } & \multirow{2}{*}{$\begin{array}{c}\mathrm{p} \\
\text { Value }\end{array}$} \\
\hline & $\begin{array}{c}\text { Unicuspid } \\
(\mathrm{n}=60[7 \%])\end{array}$ & $\begin{array}{c}\text { Bicuspid } \\
(\mathrm{n}=385[44 \%])\end{array}$ & $\begin{array}{c}\text { Tricuspid } \\
(\mathrm{n}=426[49 \%])\end{array}$ & \\
\hline Age group (years) & & & & $<0.001$ \\
\hline $21-50$ & $31(52 \%)$ & $29(8 \%)$ & $6(1 \%)$ & \\
\hline $51-70$ & $24(40 \%)$ & $206(54 \%)$ & $110(26 \%)$ & \\
\hline $71-95$ & $5(8 \%)$ & $150(39 \%)$ & $310(73 \%)$ & \\
\hline Gender & & & & 0.169 \\
\hline Male & $36(60 \%)$ & $252(65 \%)$ & $234(55 \%)$ & \\
\hline Female & $24(40 \%)$ & $133(35 \%)$ & $192(45 \%)$ & \\
\hline Race & & & & 0.274 \\
\hline White & $47(78 \%)$ & $324(84 \%)$ & $350(82 \%)$ & \\
\hline Black & $2(3 \%)$ & $12(3 \%)$ & $32(8 \%)$ & \\
\hline Hispanic & $4(7 \%)$ & $18(5 \%)$ & $13(3 \%)$ & \\
\hline Other & $7(12 \%)$ & $31(8 \%)$ & $31(7 \%)$ & \\
\hline Coronary artery bypass grafting & $11(18 \%)$ & $142(37 \%)$ & $275(65 \%)$ & $<0.001$ \\
\hline Number of major coronary arteries narrowed $\geq 50 \%$ & $(n=29)$ & $(\mathrm{n}=212)$ & $(n=236)$ & $<0.001$ \\
\hline 0 & $23(79 \%)$ & $143(67 \%)$ & $102(43 \%)$ & \\
\hline 1 & $3(10 \%)$ & $34(16 \%)$ & $52(22 \%)$ & \\
\hline 2 & $2(7 \%)$ & $23(11 \%)$ & $49(21 \%)$ & \\
\hline 3 & $1(3 \%)$ & $8(4 \%)$ & $26(11 \%)$ & \\
\hline 4 & 0 & $4(2 \%)$ & $7(3 \%)$ & \\
\hline $\begin{array}{l}\text { LV-aorta peak systolic gradient }(\mathrm{mm} \mathrm{Hg})(\mathrm{n}= \\
475) \text {, range (mean) [median] }\end{array}$ & $20-154(64)[63]$ & $11-130(55)[51]$ & $11-119(45)[41]$ & $<0.001$ \\
\hline Aortic valve area $\left(\mathrm{cm}^{2}\right)(\mathrm{n}=474)$, mean $\pm S D$ & $0.80 \pm 0.34$ & $0.78 \pm 0.25$ & $0.83 \pm 0.30$ & 0.139 \\
\hline Aortic valve weight (g), range (mean) [median] & $1.19-7.15$ (3.37) [3.17] & $0.67-18.38(3.11)[2.79]$ & $0.43-6.40(2.04)[1.92]$ & $<0.001$ \\
\hline Systemic hypertension by history & $27(45 \%)$ & $260(68 \%)$ & $329(77 \%)$ & $<0.001$ \\
\hline Body mass index $\left(\mathrm{kg} / \mathrm{m}^{2}\right)$ & & & & 0.863 \\
\hline$\leq 25$ & $24(41 \%)$ & $119(31 \%)$ & $145(34 \%)$ & \\
\hline$>25-30$ & $21(36 \%)$ & $130(34 \%)$ & $141(33 \%)$ & \\
\hline$>30-40$ & $13(22 \%)$ & $111(29 \%)$ & $121(29 \%)$ & \\
\hline$>40$ & $1(2 \%)$ & $22(6 \%)$ & $17(4 \%)$ & \\
\hline Range (mean $\pm \mathrm{SD}$ ) & $17-44(27 \pm 5)$ & $16-66(29 \pm 7)$ & $15-69(29 \pm 6)$ & \\
\hline $\begin{array}{l}\text { Days in hospital postoperatively in patients living } \\
>30 \text { days, range (mean) [median] }\end{array}$ & $3-32(7)[6]$ & $3-43(8)[6]$ & $3-71(10)[8]$ & $<0.001$ \\
\hline Died $\leq 30$ days postoperatively & $0 / 59$ & $20 / 380(5 \%)$ & $27 / 425(6 \%)$ & 0.222 \\
\hline Ascending aorta replaced & $9(15 \%)$ & $25(6 \%)$ & $3(1 \%)$ & $<0.001$ \\
\hline Implanted valve type & & & & $<0.001$ \\
\hline Mechanical & $41(68 \%)$ & $118(31 \%)$ & $53(12 \%)$ & \\
\hline Bioprosthetic & $17(28 \%)$ & $264(69 \%)$ & $371(87 \%)$ & \\
\hline Ross procedure & $2(3 \%)$ & $3(<1 \%)$ & $2(<1 \%)$ & \\
\hline
\end{tabular}

The valve structure in the 871 patients is listed in Table 2. The 426 patients (49\%) with tricuspid aortic valves, compared to the 445 patients $(51 \%)$ with either congenitally unicuspid or bicuspid valves, were significantly older ( $p<0.001)$, had much higher frequencies of concomitant CABG ( $\mathrm{p}<0.001)$, had higher likelihoods of having $\geq 1$ major epicardial coronary artery being narrowed $>50 \%$ in diameter on angiogram $(p<0.001)$, had lower transvalvular peak systolic pressure gradients ( $\mathrm{p}<0.001$ ), had lighter aortic valves by weight ( $\mathrm{p}$ $<0.001$ ), had higher frequencies of systemic hypertension $(\mathrm{p}<0.001)$, had more days in the hospital after AVR $(p<0.001)$, and had higher late $(>30$ days) mortality rates after AVR. Unadjusted early mortality (30 days) was not significantly (odds ratio $1.16,95 \%$ CI 0.56 to 2.42) different between patients with unicuspid or bicuspid versus tricuspid valves. Both unadjusted and adjusted survival, however, were significantly higher in patients with unicuspid or bicuspid valves compared to patients with tricuspid aortic valves (adjusted hazard ratio 0.70, 95\% CI 0.50 to 0.97; Figures 4 and 5).

Coronary angiographic data were available for 477 of the 871 patients $(55 \%)$. Compared to the 278 patients $(58 \%)$ in whom none of the major coronary arteries was narrowed to this degree, the 199 patients $(42 \%)$ with $\geq 1$ coronary artery narrowed $>50 \%$ were significantly older $(p=0.012)$, were more often male $(\mathrm{p}=0.005)$, had much higher frequencies of concomitant CABG ( $p<0.001$ ), had smaller peak systolic transvalvular pressure gradients $(\mathrm{p}=0.010)$ and larger valve areas $(p=0.002)$, had higher frequencies of tricuspid aortic valves and lower frequencies of congenitally malformed valves $(\mathrm{p}<0.001)$, and had smaller aortic valves by weight $(\mathrm{p}=0.030)$. 


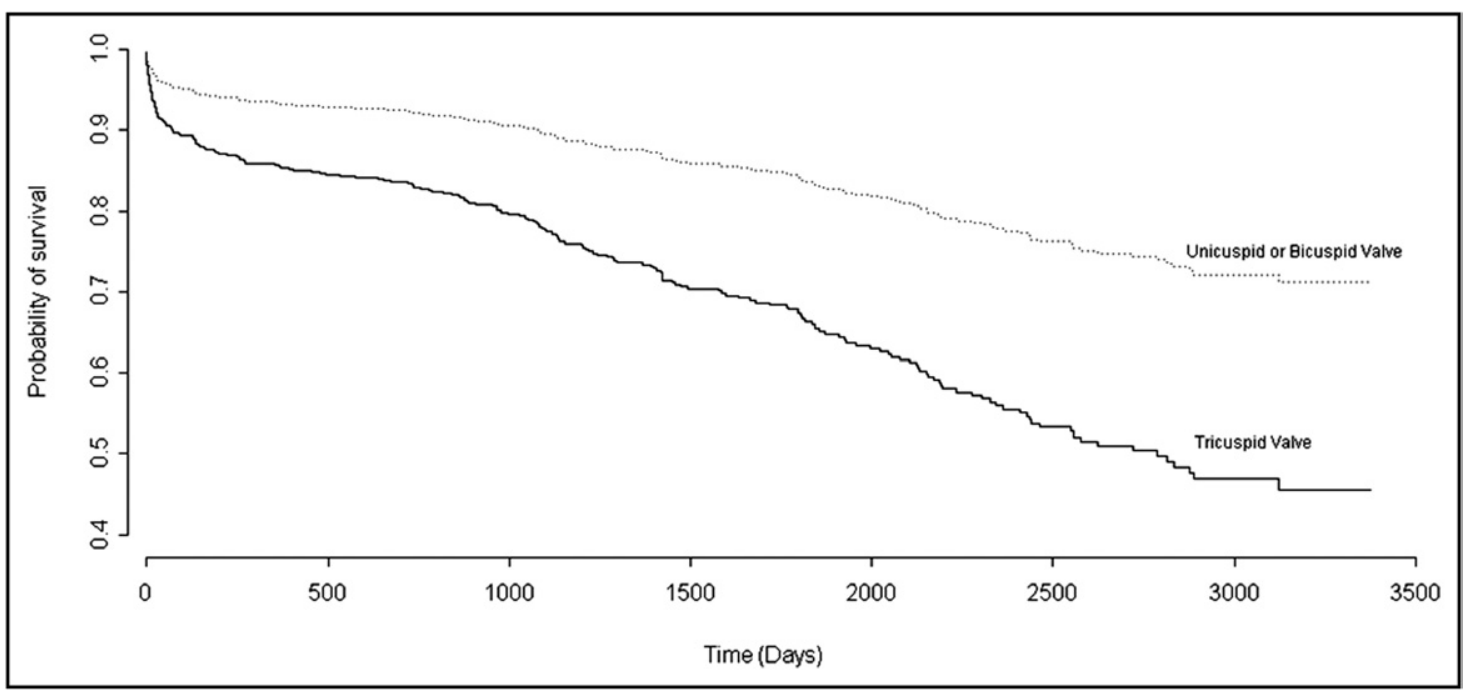

Figure 4. Unadjusted (proportional-hazards model) curves depicting significantly different survival in patients with unicuspid or bicuspid valves compared to those with tricuspid valves, all of whom underwent AVR (unadjusted hazard ratio $0.43,95 \%$ CI 0.32 to 0.57 , unadjusted $\mathrm{p}<0.001$ ).

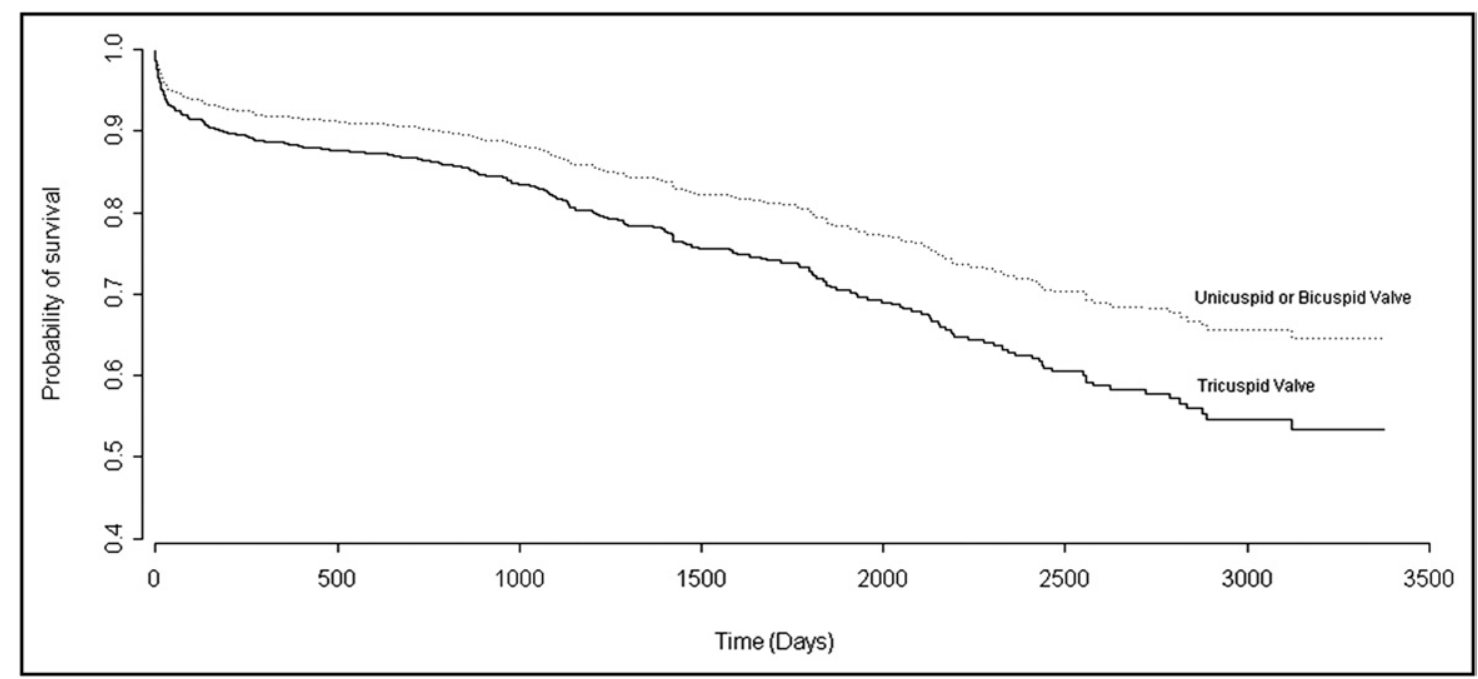

Figure 5. Adjusted (proportional-hazards model) curves depicting significantly different survival in those with unicuspid or bicuspid aortic valves compared to those with tricuspid valves, all of whom underwent AVR (adjusted hazard ratio 0.70, 95\% CI 0.50 to 0.97 , adjusted p $=0.031$ ). The propensity-adjusted model included the following risk factors: age, gender, race, body mass index, concomitant CABG, valve weight, systemic hypertension, ascending aorta replaced, and type of implanted valve.

\section{Discussion}

The present study of patients who underwent AVR for AS (with or without aortic regurgitation) examined whether simultaneous CABG (vs not) and aortic valve structure (unicuspid or bicuspid vs tricuspid) affected short- and long-term survival. Although the patients who underwent simultaneous CABG compared to those who did not were significantly older, were more often male, had smaller transvalvular peak systolic pressure gradients and larger valve areas, most often had tricuspid aortic valves and much less frequently congenitally malformed valves, had higher frequencies of systemic hypertension, and had longer hospital stays, the adjusted probability of long-term survival was no different in those with versus without concomitant CABG. The unadjusted $\mathrm{p}$ value re- garding the association between concomitant CABG (vs not) and long-term survival was 0.005 , while the adjusted $\mathrm{p}$ value was 0.976 .

None of the previously published reports of patients who underwent AVR for AS with or without simultaneous CABG focused on the structure of stenotic aortic valve. ${ }^{6-13}$ In the present study, aortic valve structure was determined by the same investigator (W.C.R.) from examination of the operatively excised valve. We found in a previous study that congruence between cardiac surgeons and cardiac pathologists regarding aortic valve structure is virtually $100 \%$ when the structure of the aortic valve is tricuspid but that it is only $56 \%$ in the case of congenitally bicuspid valves and only $15 \%$ in the case of unicuspid valves. ${ }^{14}$ Thus, uniformity of determination 
of valve structure results in far more accurate information compared to valve structure determined by several different surgeons, each of whom may have varying expertise in describing aortic valve structure or even mentioning valve structure in the operative note. Additionally, the intervals between AVR and dictation of the operative note were quite variable among surgeons, whose memories also might be quite variable. ${ }^{14}$ The present study found that among the 426 patients with tricuspid aortic valves, 65\% underwent concomitant $\mathrm{CABG}$, whereas among the 60 patients with unicuspid valves and the 385 with congenitally bicuspid valves, concomitant CABG was far less frequently performed (18\% and $37 \%$, respectively). Both unadjusted and adjusted survival was significantly better in the patients with unicuspid or bicuspid aortic valves compared to those with tricuspid aortic valves.

A bit surprising to many students of aortic valve disease was the relatively high frequency of the congenitally malformed valves in all 3 age groups examined. Among the 66 patients aged 21 to 50 years, $60(91 \%)$ had congenitally malformed aortic valves (unicuspid in 31 and bicuspid in 29); of the 340 patients aged 51 to 70 years, 230 (68\%) had congenitally malformed valves (unicuspid in 24 and bicuspid in 206); and of the 465 patients aged 71 to 95 years, 155 (33\%) had congenitally malformed valves (unicuspid in 5 and bicuspid in 150).

That CABG was significantly more frequent in the group with tricuspid aortic valves partly supports the view that $\mathrm{AS}$ in older patients with tricuspid aortic valves is the result of "atherosclerosis" involving the aortic valve. Patients with rheumatic heart disease were presumably excluded from the present study on the basis of having excluded all patients with mitral stenosis and those who underwent any operative procedure on the mitral valve (either repair or replacement).

There were limitations to the present study. Echocardiographic and hemodynamic data were not available in all patients. Not all patients with narrowing $>50 \%$ in diameter of $\geq 1$ major coronary artery underwent CABG. Many patients who underwent concomitant CABG and AVR would not have undergone AVR unless $\geq 1$ of the coronary arteries had not been quite narrowed by preoperative angiogram. A major strength of the present study is that it is the first to compare long-term survival after AVR for AS (with or without aortic regurgitation) according to the underlying valve structure (unicuspid, bicuspid, or tricuspid).

1. Harrell FE Jr. Regression Modeling Strategies: With Application to Linear Models, Logistic Regression, and Survival Analysis. New York, New York: Springer-Verlag; 2001.

2. D'Agostino RB Jr. Propensity score methods for bias reduction in the comparison of a treatment to a non-randomized control group. Stat Med 1998;17:2265-2281.

3. Filardo G, Hamilton C, Hamman B, Ng HK, Grayburn P. Categorizing BMI may lead to biased results in studies investigating in-hospital mortality after isolated CABG. J Clin Epidemiol 2007;60:1132-1139.

4. Filardo G, Hamilton C, Hamman B, Grayburn P. Obesity and stroke after cardiac surgery: the impact of grouping body mass index. Ann Thorac Surg 2007;84:720-722.

5. Grambsch PM, Therneau T. Proportional hazards tests and diagnostics based on weighted residuals. Biometrika 1994;81:515-526.

6. Jones EL, Weintraub WS, Craver JM, Guyton RA, Shen Y. Interaction of age and coronary disease after aortic valve replacement: implications for valve selection. Ann Thorac Surg 1994;58:378-385.

7. Akins CW. Long-term results with the Medtronic-Hall valvular prosthesis. Ann Thorac Surg 1996;61:806-813.

8. Litmathe J, Boeken U, Feindt P, Gams E. Concomitant CABG procedures in elderly patients undergoing aortic valve replacement. Z Kardiol 2003;92:947-952.

9. Gillinov AM, Garcia MJ. When is concomitant aortic valve replacement indicated in patients with mild to moderate stenosis undergoing coronary revascularization? Curr Sci 2005;7:101-104.

10. Kuduvalli M, Grayson AD, Au J, Grotte G, Bridgewater B, Fabri BM. A multi-centre additive and logistic risk model for in-hospital mortality following aortic valve replacement. Eur J Cardiothorac Surg 2007;31:607-613.

11. Kobayashi KJ, Williams JA, Nwakanma L, Gott VL, Baumgartner WA, Conte JV. Aortic valve replacement and concomitant coronary artery bypass: assessing the impact of multiple grafts. Ann Thorac Surg 2007;83:969-978.

12. Gulbins H, Malkoc A, Ennker J. Combined cardiac surgincal procedures in octogenarians: operative outcome. Clin Res Cardiol 2008;97: $176-180$.

13. Likosky DS, Sorensen MJ, Dacey LJ, Baribeau YR, Leavitt BJ, DiScipio AW, Hernandez F Jr, Cochran RP, Quinn R, Helm RE, Charlesworth DC, Clough RA, Malenka DJ, Sisto DA, Sardella G, Olmstead EM, Ross CS, O'Connor GT. Long-term survival of the very elderly undergoing aortic valve surgery. Circulation 2009;120:127-133.

14. Roberts WC, Vowels TJ, Ko JM. Comparison of interpretations of valve structure between cardiac surgeon and cardiac pathologist among adults having isolated aortic valve replacement for aortic valve stenosis ( \pm aortic regurgitation). Am J Cardiol 2009;103: $1139-1145$. 